\title{
Correlation of blood glucose with lipid profile levels as risks for cardiovascular disease among diabetic patients at Ruhengeri referral hospital
}

\author{
Alexis Nshimiyimana, Thierry Habyarimana, Joseph Mucumbitsi, Callixte Yadufashije, \\ and Francois N. Niyonzima*
}

\begin{abstract}
Department of Biomedical Laboratory Sciences, Faculty of Applied Fundamental Sciences, INES-Ruhengeri, Rwanda E-mail: alenshimiye@gmail.com; h.thierry@ines.ac.rw; jephmicro@gmail.com; cyadufashije@ines.ac.rw;niyofra@yahoo.com
\end{abstract}

*Corresponding author details: Dr. Niyonzima N. Francois, Email: niyofra@yahoo.com

\begin{abstract}
Dyslipidemia remains the leading cause of cardiovascular mortality and morbidity among diabetic patients. The study was conducted to describe the correlation of blood glucose and lipid profile levels as risks for cardiovascular disease among diabetic patients at Ruhengeri referral hospital. It was a crosssectional study. A total of 103 diabetic patients were recruited. The blood glucose and lipid profile levels were tested, and the cardiovascular risks were observed. The results were analyzed using SPSS version 22.0. 78.4\% of diabetic patients have dyslipidemia characterized by high LDL-C, hypercholesterolemia, hypertriglyceridemia and low HDL-C. There was a statistical significance association with BMI and TC $\left(\chi^{2}\right.$ $=21.611 ; p=0.000)$, TG $\left(\chi^{2}=14.311 ; p=0.000\right)$, and LDL-C $\left(\chi^{2}=6.367 ; p=0.012\right)$. A positive significant correlation was observed between blood glucose and TG and BMI and TC levels $(r=0.420 ; p=0.001 ;(r=$ $0.663 ; \mathrm{p}=0.001)$ respectively. Gender was statistically significant to have an effect to low Framingham risk score $\left(\chi^{2}=13.359 ; \mathrm{df}=6 ; \mathrm{p}=0.038\right)$. The study shows a high prevalence of dyslipidemia. $\mathrm{TC}$ and LDL-C are significantly increased in diabetic patients with high BMI. Co-morbidity of diabetes and dyslipidemia remains a statistically significant predictor of cardiovascular risk. Therefore, regular monitoring of lipid profile in diabetic patients would prevent incremental risk for CVD.
\end{abstract}

Keywords: lipid profile; diabetic patients; blood glucose; Ruhengeri referral hospital

\section{INTRODUCTION}

Diabetes mellitus (DM) is a syndrome characterized by disturbed metabolism of glucose and lipids and is wellknown risk factor for cardiovascular disease (CVD) [1]. The global burden of diabetes was over 451 million people in 2017 and the most affected people were in the age range of 18 to 99 years. Of 451 million people, $79 \%$ were from lowand middle-income countries. Patients having type 2 diabetes mellitus (T2DM) are more prone to the cardiovascular complications compared to people suffering from type 1 diabetic mellitus (T1DM), and diabetic patients are more affected by CVD than non-diabetic people [2].

Dyslipidemia in diabetes is the most important risk factor for CVD. It is associated with the lipid abnormalities characterized by the qualitative and quantitative changes in lipids and lipoproteins. The elevated triglyceride (TG), increased low density lipoprotein cholesterol (LDL-C) and decreased high-density lipoprotein cholesterol (HDL-C) was the common pattern of dyslipidemia in diabetic patients. Comorbidity of diabetes and dyslipidemia was found in more than $50 \%$ of diabetic patients across the world and both conditions have a synergistic effect in triggering CVD [3].

Diabetic patients who had dyslipidemia are more likely to have CVD than diabetes free people and are linked with 2 to 4 folds increased mortality in diabetic patients than in healthy people. Approximately $75 \%$ of deaths in diabetic patients were attributed to diabetes related cardiovascular complications [4]. Moreover, atherogenic cardiomyopathy was found in more than $50 \%$ of all diabetic patients and approximately $15 \%$ of patients with stroke suffered from diabetes and dyslipidemia, whereas up to $5 \%$ of diabetic patients presented atherosclerotic cerebrovascular accidents at diagnosis [5].

The prevalence of diabetes mellitus among people aged 20 to 79 years in sub-Saharan Africa (SSA) was 5.5\% in South Africa, 2.5\% in Uganda, 2.9\% in Kenya, 3.9\% in Zambia, 7.2\% in Gabon, 6.2\% in Democratic Republic of Congo, and 4.2\% in Rwanda [6]. Dyslipidemia in SSA has become a persecutor to CVD and was responsible for $59 \%$ of ischemic heart disease (IHD) and 29\% of ischemic stroke to people aged 30 years and older. Moreover, approximately $8.6 \%$ of total deaths in SSA were caused by diabetes related cardiovascular complications [7]. Rapid rises of diabetes and associated cardiovascular complications in low-resource settings are more challenging in SSA than in any other part of the world [8].

Dyslipidemia and related cardiovascular outcomes among diabetic patients from low-resource countries including Rwanda remains scanty $[9,10]$. The paucity of data related to the prevalence and pattern of dyslipidemia in diabetic patients hampered the prevention and management of CVD associated with diabetes complications [11]. Therefore, the 
assessment of the full lipid panel including TC, TG, LDL-C, and HDL-C for a holistic cardiovascular risk in diabetic is required.

\section{OBJECTIVES OF THE STUDY}

The objectives of the present study were to i) assess the prevalence and pattern of the lipid abnormalities among diabetic patients as risks for cardiovascular diseases, ii) describe the association of demographic and clinical characteristics with the lipid profile parameters, and iii) determine the correlation of blood glucose with serum triglyceride (TG), total cholesterol (TC), high density lipoprotein cholesterol (HDL-C) and low density lipoprotein cholesterol (LDL-C) levels in diabetic patients at Ruhengeri referral hospital.

\section{METHODOLOGY}

\section{Study settings}

The study was carried out at Ruhengeri referral hospital located in Northern Province of Rwanda, Musanze district. The hospital receives referred patients from 16 peripheral health centers of Musanze district and from the neighboring Gisenyi and Shyira district hospitals of Rubavu and Nyabihu districts, respectively. Analysis of blood glucose was done from capillary blood in the department of the non-communicable diseases at the hospital. Venous blood specimen were then collected and transported for further analysis at the INESRuhengeri clinical biochemistry laboratory.

\section{Study design}

This cross-sectional and prospective study conducted to the correlation of blood glucose with lipid profile levels in diabetic patients at Ruhengeri referral hospital. All diabetic outpatients who attended Ruhengeri hospital from November 2018 to January 2019 and who were eligible with inclusion criteria and consented to participate in the study were recruited.

\section{Study population}

All diabetic patients who attended the non-communicable diseases clinic at Ruhengeri referral hospital during the period from November 2018 to January 2019 were targeted by the study. However, only 103 patients who met inclusion criteria were recruited for the study participation.

\section{Inclusion and exclusion criteria}

All patients with diabetes mellitus aged 21 years and above, in fasting state for overnight and without documented history of cardiovascular disease were recruited for the study. Pregnant women with gestational diabetes mellitus, diabetic patients who ever have been treated for cardiovascular event or under CVD treatment and patients under lipids lowering therapy during the time of the study were not eligible for the study.

\section{Data sources and participants}

The age and time in diabetic follow up of the study participants were recorded from the patients' medical file. Blood pressure reading was taken from diabetic patients by a nurse using the Belsk digital blood pressure monitor. Hypertension was considered with systolic blood pressure of $140 \mathrm{mmHg}$ or higher and diastolic blood pressure of $90 \mathrm{mmHg}$ or above [12]. Capillary blood samples were drawn by the researcher and tested for fasting blood glucose using Accu-Check Aviva device. The normal ranges for the glucose results were for values between $75-120 \mathrm{mg} /$ [13]. The body weight and height were taken by the researcher using mechanical height and body weight measuring instrument (Brecknell HS$200 \mathrm{M}$ ). All the results were recorded in the patients' medical files.
The BMI was calculated as the ratio of a person's weight in kilograms by the square of his/her height in meters $\left(\mathrm{kg} / \mathrm{m}^{2}\right)$ and categorized as underweight: BMI $<18.5$ $\mathrm{kg} / \mathrm{m}^{2}$, normal weight: $18.5 \leq \mathrm{BMI} \leq 24.9 \mathrm{~kg} / \mathrm{m}^{2}$, overweight: $25 \leq \mathrm{BMI}<30 \mathrm{~kg} / \mathrm{m}^{2}$, and obese: $\mathrm{BMI} \geq 30$ $\mathrm{kg} / \mathrm{m}^{2}$ [14]. All the results were transcribed into Microsoft excel spreadsheet for subsequent analyses. 4 $\mathrm{ml}$ of venous blood was collected from each diabetic patient in a red top tube with clot activator using a needle green G21 and allowed to clot. The methods for data collection are described in-depth elsewhere.

\section{Laboratory analysis}

The collected venous blood specimens were transported to the clinical biochemistry laboratory of INES-Ruhengeri and processed for TC, TG, and HDL-C tests using Humastar 80 auto analyzer. The normal values were established according to the National Cholesterol Education Program (NCEP) Adult Treatment Panel III (ATP III) as per Yu et al. [15] with TC $<200 \mathrm{mg} / \mathrm{dl}, \mathrm{TG}<150 \mathrm{mg} / \mathrm{dl}$, HDL-C between $41-60 \mathrm{mg} / \mathrm{dl}$ for males and $51-60 \mathrm{mg} / \mathrm{dl}$ for females, and low LDL-C $<100 \mathrm{mg} / \mathrm{dl}$. The calculation of low density lipoprotein-cholesterol (LDL-C) utilized the modified Friedewald equation as follows: LDL-C $(\mathrm{mg} / \mathrm{dl})=($ NonHDL-C $\times 90 \%)-(T G \times 10 \%)$ [16]. The general CVD risk score tool developed by Framingham was utilized to assess risk for CVD risk. The risk score was computed using the individual's age, arterial blood pressure, TC, HDL-C, and blood glucose. The risk for CVD was graded as low, moderate and high with $<10,10$ to 20 and $>20 \%$ scores, respectively [17]. SPSS version 22 was used for data analysis.

\section{Ethical consideration}

The permission to conduct the research was granted by both Ruhengeri referral hospital and INES Ruhengeri ethical committees. Diabetic patients were informed about the study and its benefits. Patients who were eligible and who voluntarily consented to participate were enrolled in the study. The right to privacy and confidentiality was respected. Collected specimens were assigned anonymous codes and data generated were solely used for the purpose of the study.

\section{Limitations of the study}

Results from this study should not be generalized to the national level due to a small sample size drawn from a small catching area in one Province of Rwanda.

\section{RESULTS AND DISCUSSION Demographic and clinical characteristics of diabetic patients}

In the present study, the correlation of blood glucose and lipid profile levels in diabetic patients at Ruhengeri referral hospital was assessed. The study enrolled 103 patients in follow-up for diabetes with female majority. The mean age and the prevalence of diabetes were more elevated in females than in males (Table 1). This is in agreement with Hilawe et al. [18] and consistent with Wändell and Carlsson [19] who argued that sex hormones and sexrelated lifestyle may lead to higher prevalence of diabetes and glycemic burden in females than in males.

The range and mean values of glycaemia were higher in females than in males and this might be in correlation with BMI disparities observed between genders. Although all study participants had diabetes, the results in table 1 show that glucose ranges in both sexes overlap with normal glycemic ranges. The results would imply that diabetes was successfully controlled in patients with normal glycaemia. In addition to systolic blood pressure which was slightly higher in female than in males, the mean BMI was in the overweight ranges and higher in females. 
The result agrees with Dixit et al. [20] who found higher mean values of glycaemia in diabetic females than males.

\section{Prevalence of dyslipidemia}

The results of the present study show a high prevalence of dyslipidemia in diabetic patients (78.4\%). The finding is consistent with Borles et al. [21] in India and in agreement with Shrestha and Khanal [22] in Nepal who reported a high prevalence of dyslipidemia (85.3 and 86\%), respectively. However, higher prevalence of $95 \%$ in Tanzania [23] and 94\% in Pakistan [24] was also reported. The differences in prevalence may be due to diverse lifestyles, difference in dietary patterns in the study populations and effectiveness of diabetes management. Lower prevalence of $20 \%$ found at Muhima district hospital [10] and 28\% at Rwanda military hospital [25] might be due to differing lipid profile test cut-off values used. The obtained results impel to screen dyslipidemia in diabetic patients in order to prevent incremental risk for CVD.

\section{Pattern of dyslipidemia}

Diabetes mellitus affects the blood lipid levels due to the relationship between the metabolism of carbohydrates and lipids. Disorders in carbohydrates metabolism lead to changes in various lipids concentration and inversely [26]. According to Mehnaz et al. [27], the most common pattern of diabetic dyslipidemia involves raised TG and TC, increased concentration of LDL-C and reduced HDL that infrequently occurs in diabetic patients. In the present study, elevated serum LDL-C level (73.8\%) was frequently recorded in lipid abnormality. Frequencies of elevated TG (hypertriglyceridemia, 38.8\%), TC (hypercholesterolemia, 46.6\%), and decreased HDL-C (26.2\%) were also found.

Similarly, Dixit et al. [20] and Niyibizi at al. [10] also found high frequency of dyslipidemia in diabetic patients. However, lower frequencies of lipid abnormalities were reported by Ashimwe [25] due to cut-off values used. The frequency of low HDL-C seen in this study $(26.2 \%)$ is consistent with other finding [28] and the frequency of elevated TG has been reported by Mehnaz et al. [27]. Thus, the frequency of lipid abnormalities observed can explain the increasing rate of CVD reported in diabetic patients and impel for early screening, treatment, and dyslipidemia control to alleviate the burden of CVD in diabetic patients.

\section{Association of demographic and clinical characteristics with dyslipidemia}

Age, gender, blood glucose levels, BMI and hypertension were reported to be linked with dyslipidemia in diabetic patients. In addition LDL-C, TC, HDL-C, and TG were associated with BMI. Moreover, an important linkage was statistically seen between dyslipidemia and BMI $[15,29$, $30]$. Results in the table 2 shows that no significant association was recorded with age. The results are comparable with Omotoye and Tanimoowo [31] and would mean that dyslipidemia may occur in diabetes regardless of the age of the patient. However, conflicting results showed that the age of diabetic patients was associated significantly with hypertriglyceridemia and elevated LDL-C [28] and further research would untie the paradox.

A review of the rates of dyslipidemia in diabetic patients showed more frequencies in diabetic females than in males [6]. As presented in Table 2, lipid abnormalities were more common in females than in males. This may be a random finding given that none of the lipid profile variables was significantly associated with gender. In contrast, significant association was between female gender and frequencies of hypercholesterolemia [28]. It may be thought that hyperlipidemia disparities between genders are attributable to sex hormones. If such is the case, it would mean that females are more likely exposed to dyslipidemia adverse effects than males.

Overweight and obesity are well known determinants of dyslipidemia in diabetic patients [32, 33]. Table 2 results show a significant association between the BMI and TC, TG and LDL-C, but the association was not significant for HDLC. In addition, as shown in table 2, high LDL-C was found more often in hypertensive diabetic patients who had diabetes for over 5 years, but no significant association was noted. The results agreed with those reported by Yu et al. [15] who argued that the duration of uncontrolled diabetes compounded with hypertension could increase the risk for atherogenic dyslipidemia. Therefore, the screening of dyslipidaemia in overweight diabetic patients with hypertension should be done to mitigate the risk for associated CVD.

\section{Relationship between gender and lipid parameters in diabetic patients}

Diabetes confers a noticeably higher risk for CVD due to frequent lipids abnormalities and diabetic females are prone to more adverse cardiovascular risks than males [34]. The association between gender and lipid parameters did not show significance as neither of the lipid parameters means differed significantly between males and females (Table 3). This corroborates with previous study that showed no significant different in mean results of lipid profile parameters between genders [35]. However, contrasting results were reported by Omotoye and Tanimoowo [31], Hussain et al. [36] and Li et al. [2] who proved that the level of HDL-C was higher in females than in males. It can be argued that sex hormones may confer a difference in dyslipidemia with the levels of HDL-C differing between females and males.

\section{Correlation between blood glucose and serum triglyceride levels}

It has been proved that diabetes mellitus is associated with hypertriglyceridemia and an increased risk for CVD [37]. Other study also associated the high triglyceride levels to hype glycaemia in diabetes patients [27]. There is a positive correlation between blood glucose and triglyceride levels as shown in Figure 1. The results are comparable to those found by Khan et al. [35] who reported statistically significant positive correlation between blood glucose and high TG. Hussain et al. [36] and Ashimwe [25] also correlated the levels of blood glucose and TG. It may be thought that blood glucose levels can be used to predict the serum TG levels and cardiovascular risk. However, dyslipidemia is considered as the potent indicator for cardiovascular risk assessment.

\section{Correlation between blood glucose and serum total cholesterol levels}

In diabetes, the serum TC levels are usually normal or nearly normal in adequate glycemic control and worsen if the control of glycaemia fails [31]. A weak positive correlation was found between blood glucose and serum TC (Fig. 2). Similarly, Mahato et al. [37] described a nonsignificant weak positive correlation of blood glucose and TC in patients with diabetes. This is in agreement with Khan et al. [35] who found positive correlations between blood glucose and serum TC. Ultimately, the results imply that hyperglycemia in diabetic patients would correspond with hypercholesterolemia. However, the correlation is not significant in most of the studies. 


\section{Correlation between blood glucose and serum LDL-C levels}

Raised blood glucose in diabetic patients has been incriminated in increasing LDL particles which are intimately implicated in triggering atherosclerotic CVD [38]. The absence of correlation between the blood glucose and serum LDL-C levels (Fig. 3) agrees with Khan et al. [35] who reported that the variations of blood glucose levels did not affect the serum levels of LDL-C. The lack of association between blood glucose and LDL was noted by Omotoye and Tanimoowo [31]. The results were also supported by Al-Adsani et al. [39] who found little or no disagreement in levels of LDL-C in diabetic and healthy people. However, the observation was contrasted by Siraj [40] who reported less frequencies of high LDL-C in healthy than in diabetic people. Therefore, due to contrasting findings, glycaemia could not be used to predict upraised levels of the serum LDL-C.

\section{Correlation of blood glucose with serum HDL-C levels} According to Khera et al. [41], lower than normal amounts of serum HDL-C in people with diabetes correspond with a deficiency in controlling the blood glucose and lead to hyperglycemia, whereas patients with adequate control of blood glucose have increased levels of serum HDL-C. The absence of association between blood glucose and HDL-C levels but an inverse and no-significant relationship was found between the 2 variables (Fig. 4). In contrast, the quantity of HDL-C was lower in the serum of patients with high glycaemia as compared to patients with effective control of diabetes [36]. Thus, lowering hyperglycemia would correspond with increasing the serum HDL-C level. However, the lack of significance in the present study would not allow ascertaining this statement.

Correlation of BMI with serum total cholesterol levels Dyslipidemia is frequently encountered in patients with diabetes particularly in overweight and obese patients and it was connected with risk for CVD [42]. An important positive correlation was seen between BMI and TC (Fig. 5) and the results mean that increase in body weight corresponds with increase of serum cholesterol. This is consistent with Yu et al. [15] who reported that hypercholesterolemia was significantly associated with BMI and compatible with Jeenduang et al. [33] who found that overweight increased the risk of lipid abnormalities in diabetic patients. The results would explain the reason why overweight and obese people are at greater risk for CVD than normal weight people.

\section{Levels of risk for cardiovascular diseases in diabetic patients}

Cardiovascular complications of diabetes are the most common cause of mortality among diabetic patients and women are at greater risk for CVD compared to men $[43,44]$. As shown in the table 4 , more females than males were at high risk for CVD. However, the reverse was observed for the moderate risk pattern for which more males were at risk than females but the risk difference between genders was not significant. Similarly, the Framingham study reported that the annual rate of CVD was the same in diabetic men and women [45]. The result was also in agreement with Sattar [46] who established that diabetes linked with increased risk for CVD in both female and male genders. Conversely, Abdel-Maksoud et al. [11] and Venkatesh et al. [47] indicated that dyslipidemia and CVD patterns were observed more frequently in females than they were in males. They argued that the body weight increase in women during menopause may be the cause of that difference. From the results it may be considered that diabetic males and females are equally prone to adverse effects of CVD and screening would mitigate the risk in both sexes.

\section{CONCLUSION}

The study revealed that more females than males were diabetic and this might be due to higher BMI frequencies observed in females than in males. In addition, a high prevalence of dyslipidemia independently of the age, gender, hypertension and period of time with diabetes but associated with BMI was observed in diabetic patients. Moreover, there was a significant correlation of blood glucose and serum TG quantities. Weak correlation of blood glucose levels and TC and the absence of correlations with LDL-C and HDL-C indicated that glycaemia was not a predictor for cholesterolemia in diabetic patients. Almost half of the diabetic patients were at elevated risk for CVD and the risk was not associated with gender. Therefore, diagnoses of dyslipidemia could rely on the full lipid panel for assessment the risk for CVD. In view of the high prevalence of dyslipidemia in diabetic at Ruhengeri referral hospital, more cross-sectional and longitudinal studies should be done to estimate the country-wide prevalence and patterns of dyslipidemia, and to ascertain cardiovascular risks associated with dyslipidemia.

\section{ACKNOWLEDGEMENTS}

This work was supported by INES Ruhengeri and Ruhengeri referral hospital.

\section{REFERENCES}

[1] Baena-Diez, J. M., Penafiel, J., \& Subirana, I. (2016). Risk of cause specific death in individuals with diabetes: a competing risks analysis. Diabetes Care, 39(11), 1987-1995. doi: 10.2337/dc16-0614

[2] Li, Y., Zhao, L., Yu, D., \& Ding, G. (2018). The prevalence and risk factors of dyslipidemia in different diabetic progression stages among middle-aged and elderly populations in China. PLoS One. doi: 10.1371/j.0205709.

[3] Mancini, G. B. J., Hegele, R. A., \& Leiter, L., A. (2018). Diabetes Canada clinical practice guidelines. Canadian Journal of Diabetes, 4(2), 178-185.

[4] Tancredi, M., Rosengren, A., Svensson, A. M., Kosiborod, M., Pivodic, A., Gudbjörnsdottir, S., \& Lind, M. (2015). Excess mortality among persons with type 2 diabetes. New England Journal of Medicine, 7(3), 1720-1732. doi: 10.1056/NEJMoa1504347

[5] Lee, K. S., Moser, D. K., Lennie, T. A., Pelter, M. M., Nesbitt, T., Southard, J. A., \& Dracut, K. (2017). Obesity paradox: comparison of heart failure patients with and without comorbid diabetes. American Journal of Critical Care, 2(6), 140-148. doi: 10.4037/ajcc2017634

[6] International Diabetes Federation. (2017). Diabetes Atlas ( $8^{\text {th }}$ ed.). The global factsheet. Retrieved from: https://www.idf.org/sites/default/files/Atlas-poster.

[7] Kiplagat, S. V., Kaduka, L., Kamano, J., \& Makworo, D. (2017). Prevalence of dyslipidemia and the associated factors among type 2 diabetes patients in Turbo subCounty, Kenya. Journal of Endocrinology and Diabetes, 4(5), 1-9. doi: 10.15226/2374-6890/4/5/00190

[8] Pastakia, S. D., Pekny, C. R., Manyara, S. M., \& Fischer, L. (2017). Diabetes in sub-Saharan Africa from policy to practice progress: targeting the existing gaps for future care for diabetes. Targets and Therapy, 10(4), 247-263. doi: 10.2147/DMSO.S126314

[9] Rudasingwa, G. J., Amendezo, E., \& Twagirumukiza, M. (2012). Clinical patterns and complications of African diabetic patients: preliminary data from Kigali university teaching hospital, Rwanda. African Journal of Diabetes Medicine, 20(2), 39-42 
[10] Niyibizi, J. B., Mutangana, M., Uwase, N., \& Ndagijimana, I. (2018). Prevalence of dyslipidemia and its associated risk factors among diabetic patients attending Muhima district hospital, Kigali city, Rwanda. World Journal of Biochemistry and Molecular Biology, 3(2), 66-71.

[11] Abdel-Maksoud, M. F., Eckel, R. H., Hamman, R. F., \& Hokanson, J. E. (2012). Risk of coronary heart disease is associated with triglycerides and high density lipoprotein cholesterol in women and nonhigh density lipoprotein cholesterol in men. Journal of Clinical Lipidology, 6(3), 374-381. doi: 10.1016/j.jacl.2012.02.011.

[12] Lu, Y., Lu, M., Dai1, H., Yang, P., Smith-Gagen, J., Miao, R., Zhong, H.,... \& Yuan, H. (2016). Lifestyle and risk of hypertension: follow-up of a young prehypertensive cohort. International Journal of Medical Sciences, 12(7), 605-612. doi: 10.7150/ijms.12446

[13] American Diabetes Association. (2017). Classification and diagnosis of diabetes. Diabetes Care, 40, S11-S24. doi: 10.2337/dc17-S005

[14] Jensen, M. D., Ryan, D. H., Apovian, C. M., Ard, J. D., Comuzzie, A. G., Donato, K. A., Hu, F. B., Hubbard, V. S., Jakicic, J. M., Kushner, R. F., Loria, C. M., Millen, B. E., Nonas, C. A., Pi-Sunyer, F. X., Stevens, J., Stevens, V. J., Wadden, T. A., Wolfe, B. M., Yanovski, S. Z. (2014). AHA/ACC/TOS guideline for the management of overweight and obesity in adults: a report of the American College of Cardiology/American Heart Association Task Force on Practice Guidelines and The Obesity Society. The Journal of the American College of Cardiology, 63(25), 2985-3023. doi: 10.1016/j.jacc.2013.11.004.

[15] Yu, S., Yang, H., Guo, X., Zhang, X., Zheng, L., \& Sun, Y. (2015). Prevalence of dyslipidemia and associated factors among the hypertensive population from rural Northeast China. Biomedical Central of Public Health, 15(1), 11-52. doi: 10.1186/s12889-0152486-7

[16] Chen, Y., Zhang, X., Pan, B., Jin, X., Yao, H., \& Chen, B. (2010). A modified formula for calculating low density lipoprotein cholesterol values. Lipids in Health and Diseases Journal, 9(2), 52-57. doi: 10.1186/1476-511X-9-52

[17] Khalili, D., Hadaegh, F., \& Soori, H. (2012). Clinical usefulness of the Framingham cardiovascular risk profile beyond its statistical performance: the Tehran lipid and glucose study. American Journal of Epidemiology, 17(6), 177-186. doi: $10.1093 /$ aje/kws204

[18] Hilawe, E. H., Yatsuyah, H., \& Kawaguchi, L. (2013). Differences by sex in the prevalence of diabetes mellitus impaired fasting glycaemia and impaired glucose tolerance in sub-Saharan Africa: a systematic review and meta-analysis. The Bulletin of WHO, 91(9), 621-715. doi: 10.2471/BLT.12.113415

[19] Wändell, P. E., \& Carlsson, C. A. (2014). Gender differences and time trends in incidence and prevalence of type 2 diabetes in Sweden. A model explaining the diabetes epidemiology worldwide today? Doi: $10.1016 /$ j.diabres

[20] Dixit, A. K., Dey, R., Suresh, A., Chaudhuri, S., Panda, A. K., Mitra, A., \& Hazra, J. (2014). The prevalence of dyslipidemia in patients with diabetes mellitus of Ayurveda Hospital. Journal of Diabetes and Metabolic Disorders, 20(4), 13-58. doi: 10.1186/2251-6581-1358

[21] Borle, A. L., Chari, N., Gupta, G., \& Bathma, V. (2016). Study of prevalence and pattern of dyslipidemia in type 2 diabetes mellitus patients attending rural health training center of medical college in Bhopal, India. International Journal of Community Medicine and Public Health, 3(1), 28-42. doi: 10.18203/23946040.ijcmph20151549

[22] Shrestha, K., \& Khanal, L. (2017). Prevalence and pattern of dyslipidemia among type 2 diabetes mellitus in a tertiary center hospital of Nepal. International Journal of Endocrinology and Metabolism, 4(3), 18-24. doi: 10.15406/emij.2017.04.00084

[23] Chattanda, S. P., \& Mgonda, Y. M. (2008). Diabetic dyslipidemia among diabetic patients attending specialized clinics in Dar es Salaam. Tanzania Medical Journal, 23(1), 8-11. doi; 10.4314/tmj.v23i1.39221

[24] Saeed, A. A. (2013). Anthropometric predictors of dyslipidemia among adults in Saudi Arabia. Journal of Epidemiology, Biostatistics and Public Health. doi: $10.2427 / 8733$

[25] Ashimwe, V. (2019). Assessment of glycated hemoglobin and correlation with lipid profile among diabetic patients attending Rwanda military hospital (Dissertation). INES Ruhengeri, Musanze.

[26] Chatterjee, M. N., \& Shinde, R. (2005). Text Book of Medical Laboratory Technology. Metabolism of Carbohydrates (6 $6^{\text {th }}$ ed.). pp 266-330. Delhi, India: Jaypee Brothers Medical Publisher.

[27] Mehnaz, K., Asif, N., Khan, J. A., \& Farw, U. (2018). Dyslipidemia in type 2 diabetes mellitus. Journal of Islamic International Medical College, 13(3), 58-69.

[28] Abdel-Aal, N., Ahmad, A., Froelicher, E., Batieha, A. M. S. Hamza, M. M. \& Ajlouni, K. M. (2008). Prevalence of dyslipidemia in patients with type 2 diabetes in Jordan. Saudi Medical Journal, 29(3), 1423-1428.

[29] Zhang, X., Sun, Z., Zheng, L., Li, J., Liu, S., \& Xu, C. (2007). Prevalence of dyslipidemia and associated factors among the hypertensive rural Chinese population. Archives of Medical Research, 38(1), 432-443. doi: 10.1186/s12889-015-2486-7

[30] Wang, S., Xu, L., Jonas, J. B., You, Q. S., Wang, Y. X., \& Yang, H. (2011). Prevalence and associated factors of dyslipidemia in the adult Chinese population. PLoS One 6(3): e17326. doi:10.1371/.0017326.

[31] Omotoye, F. E., \& Tanimoowo, G. F. (2016). Association between glycemic control and serum lipid profile of type 2 diabetic patients in university hospital Ibadan, Nigeria. Journal of Food and Nutrition Sciences, 4(4), 98-102. doi: 10.11648/j.jfns.20160404.14

[32] Cai, L., Zhang, L., Liu, A., Li, S., \& Wang, P. (2012). Prevalence, awareness, treatment, and control of dyslipidemia among adults in Beijing, China. Journal for Atherosclerosis and Thrombosis, 19(7), 159-168. doi: 10.5551/jat.10116

[33] Jeenduang, N., Whanmasae, S., Seepawin, P., \& Kullabootr, S. (2013). The prevalence of dyslipidemia among a rural Thai population in the Nakhon Si Thammarat province. The Journal of the Medical Association of Thailand, 9(6), 992-1000.

[34] Regitz-Zagrosek, V., Lehmkuhl, E., \& Mahmoodzadeh, S. (2007). Gender aspects of the role of the metabolic syndrome as a risk factor for cardiovascular disease.Gender Medicine, 7(4) 16 21-1677. doi: 10.1016/s1550-8579(07)80056-8

[35] Khan, H. A., Sobki, S. H., \& Khan, S. A. (2007). Association between glycemic control and serum lipid profile in type 2 diabetic patients: HbA1c predicts dyslipidemia. Clinical and Experimental Medicine, 7(1), 24-29.

[36] Hussain, A., Ali, I., Ijaz, M., \& Rahim, A. (2017). Correlation between hemoglobin A1c and serum lipid profile in Afghani patients with type 2 diabetes: hemoglobin A1c prognosticates dyslipidemia. Therapeutic Advances in Endocrinology and Metabolism, 12(5), 51-57. doi:10.1177/204201881769229 
[37] Mahato, R. V., Gyawali, P., Raut, P. P., Regmi, P., Singh, P. K., Pandey, D. R.,\& Gyawali, P. (2011). Association between glycaemia control and serum lipid profile in type 2 diabetic patients: glycated hemoglobin as a dual biomarker. Biomedical Research Journal, 22(3), 375-380.

[38] Woollett, L. A. (2005). Maternal cholesterol in fetal development: transport of cholesterol from the maternal to fetal circulation. American Journal of Clinical Nutrition, 8(2), 1155-1161. doi: 10.1093/ajcn/82.6.1155

[39] Al-Adsani, A., Memon, A., \& Suresh, A. (2004). Pattern and determinants of dyslipidemia in type 2 diabetes mellitus patients in Kuwait. Acta Diabetologia, 4(1), 129-135. doi: 10.1007/s00592-004-0156-9

[40] Siraj, E. S., Seyoum, B., Saenz, C., \& Abdulkadir, J. (2006). Lipid and lipoprotein profiles in Ethiopian patients with diabetes mellitus. Metabolism, 5 (5), 706-710. doi: 10.1016/j.metabol.2005.08.002

[41] Khera, A. V., Cuchel, M., de la Llera-Moya, M., Rodrigues, A., Burke, M. F., Jafri, K., French, B. C., \& Rader, D. J. (2011). Cholesterol efflux capacity, high density lipoprotein function and atherosclerosis. New England Journal of Medicine, 36(4), 127-135. doi: 10.1056/NEJMoa1001689
[42] National Cholesterol Education Program. (2002). Expert panel on detection, evaluation and treatment of high blood cholesterol in adults treatment panel III. Final report. Circulation, 106(31), 143-421.

[43] Arnetz, L., Ekberg, N. R., \& Alvarsson, M. (2014). Sex differences in type 2 diabetes: focus on disease course and outcomes. Diabetes, metabolic syndrome and obesity: Targets and Therapy, 7(1), 409-420. doi: 10.2147/DMSO.S51301

[44] Peters, S. A., Huxley, R. R., \& Woodward, M. (2014). Diabetes as risk factor for incident coronary heart disease in women compared with men: a systematic review and meta-analysis of 64 cohorts including 858,507 individuals and 28,203 coronary events. Diabetologia, 57(8), 1542-1551. doi: 10.1007/s00125-014-3260-6

[45] Kannel, W. B., \& McGee, D. L. (1979). Diabetes and cardiovascular disease. The Framingham study. The Journal of the American Medical Association, 41(19), 2035-2038. doi:10.1001/jama.1979.03290450033020

[46] Sattar, N. (2013). Gender aspects in type 2 diabetes mellitus and cardio-metabolic risk. Best Practices and Research Clinical Endocrinology Metabolism, 27(4), 501-507. doi: 10.1016/j.beem.2013.05.006

[47] Venkatesh, S. K., Sudheer, K. M. V., \& Krishna, M. T. (2018). Lipid profile analysis of type 2 diabetic patients in Bengaluru, India. International Journal of Research in Medical Sciences, 6(6), 2049-2053. doi:10.18203/2320-6012.ijrms20182286

TABLE 1: DEMOGRAPHIC AND CLINICAL CHARACTERISTICS OF DIABETIC PATIENTS

\begin{tabular}{lcccc}
\hline \multirow{2}{*}{\multicolumn{1}{c}{ Characteristics }} & \multicolumn{2}{c}{ Males(n=22) } & Females (n=81) \\
\cline { 2 - 5 } & Ranges & Mean & Ranges & Mean \\
\hline Age (years) & $25-92$ & 57.6 & $23-93$ & 60.4 \\
Blood glucose (mg/dl) & $92-376$ & 173.3 & $92-567$ & 176.0 \\
Systolic blood pressure (mm/Hg) & $117-209$ & 153.5 & $92-217$ & 153.4 \\
Body mass index (kg/ $\mathbf{~ m}^{\mathbf{2}}$ ) & $18.6-33.7$ & 24.7 & $18.6-44.1$ & 26.2 \\
Duration of diabetes(years) & 1 to 11 & 3.4 & 1 to 11 & 3.9 \\
\hline
\end{tabular}


TABLE 2: ASSOCIATION OF DEMOGRAPHIC AND CLINICAL CHARACTERISTICS WITH DYSLIPIDEMIA

$\mathrm{n}=\mathbf{1 0 3}$

\begin{tabular}{|c|c|c|c|c|c|}
\hline Variables & $\begin{array}{c}\text { Number } \\
\text { of } \\
\text { patients }\end{array}$ & $\begin{array}{c}\text { Hypercholesterolemia } \\
\text { n (\%) }\end{array}$ & $\begin{array}{c}\text { Hypertriglyceridemia } \\
\text { n (\%) }\end{array}$ & $\begin{array}{c}\text { Low } \\
\text { HDL-C } \\
\text { n (\%) }\end{array}$ & $\begin{array}{c}\text { High } \\
\text { LDL-C } \\
\text { n (\%) }\end{array}$ \\
\hline \multicolumn{6}{|l|}{ Age (years) } \\
\hline$[20-40]$ & 9 & $5(55.6)$ & $4(44.4)$ & $2(22.2)$ & $8(88.9)$ \\
\hline [41-60] & 42 & $22(47.6)$ & $16(38.1)$ & $12(28.6)$ & $30(71.4)$ \\
\hline$>60$ & 52 & $23(44.2)$ & $20(38.5)$ & $13(25.0)$ & $38(73.1)$ \\
\hline Chi square test & & 0.132 & 0.102 & 0.316 & 1.260 \\
\hline p-value & & 0.936 & 0.95 & 0.854 & 0.533 \\
\hline \multicolumn{6}{|l|}{ Sex } \\
\hline Male & 22 & $10(45.5)$ & $6(27.3)$ & $4(18.2)$ & $15(68.2)$ \\
\hline Female & 81 & $38(46.9)$ & $34(42.0)$ & $23(28.4)$ & $61(75.3)$ \\
\hline Chi square test & & 0.015 & 1.334 & 0.722 & 0.825 \\
\hline p-value & & 0.903 & 0.248 & 0.395 & 0.364 \\
\hline \multicolumn{6}{|l|}{ BMI (kg/m2) } \\
\hline BMI 18.5 - 24.9 ) & 52 & $17(33.0)$ & $10(19.2)$ & $11(21.6)$ & $33(63.5)$ \\
\hline BMI >25) & 51 & $37(72.5)$ & $30(57.7)$ & $14(27.0)$ & $44(84.6)$ \\
\hline Chi square test & & 21.611 & 14.311 & 0.336 & 6.367 \\
\hline p-value & & $0.0001^{*}$ & $0.0001^{*}$ & 0.562 & $0.012^{*}$ \\
\hline \multicolumn{6}{|c|}{ Blood pressure (mmHg) } \\
\hline Hypertension & 81 & 37 (45.7) & $35(43.2)$ & $24(29.7)$ & $50(74.1)$ \\
\hline Non hypertension & 22 & $11(50.0)$ & $5(22.7)$ & $3(13.6)$ & $16(72.7)$ \\
\hline Chi square test & & 0.152 & 0.003 & 1.209 & 0.088 \\
\hline p-value & & 0.697 & 0.959 & 0.271 & 0.767 \\
\hline \multicolumn{6}{|c|}{$\begin{array}{l}\text { Time of diabetes follow up } \\
\text { (years) }\end{array}$} \\
\hline$<5$ & 72 & $31(43.0)$ & $27(37.5)$ & $19(26.4)$ & $51(70.8)$ \\
\hline$[5-10]$ & 25 & $15(60.0)$ & $12(48.0)$ & $5(20.0)$ & $21(84.0)$ \\
\hline$>10$ & 6 & $2(33.3)$ & $2(33.3)$ & $3(50.0)$ & $4(66.7)$ \\
\hline Chi square test & & 1.731 & 0.999 & 0.581 & 1.476 \\
\hline p-value & & 0.421 & 0.607 & 0.748 & 0.478 \\
\hline
\end{tabular}

*significant at $\mathbf{p}<0.05$

TABLE 3: COMPARISON OF MEANS OF LIPID PROFILE PARAMETERS BY GENDER

$\mathrm{n}=103$

\begin{tabular}{|c|c|c|c|c|c|c|c|}
\hline \multirow[t]{2}{*}{ Parameters } & \multicolumn{2}{|c|}{$\begin{array}{l}\text { Male patients } \\
(n=22)\end{array}$} & \multicolumn{2}{|c|}{$\begin{array}{l}\text { Female patients } \\
\qquad(\mathrm{n}=81)\end{array}$} & \multirow{2}{*}{$\begin{array}{c}\text { Independent } \\
\text { t-test }\end{array}$} & \multirow{2}{*}{$\begin{array}{l}\text { Degree of } \\
\text { freedom }\end{array}$} & \multirow[t]{2}{*}{ p-value } \\
\hline & Mean & SD & Mean & SD & & & \\
\hline $\begin{array}{l}\text { Total cholesterol } \\
\text { (mg/dl) }\end{array}$ & 196.9 & 53.1 & 198.4 & 50.1 & 0.125 & 101 & 0.901 \\
\hline Triglycerides (mg/dl) & 145.6 & 42.4 & 156.9 & 54.0 & 0.907 & 101 & 0.367 \\
\hline HDL-C (mg/dl) & 43.3 & 5.8 & 42.1 & 4.9 & -0.917 & 101 & 0.362 \\
\hline LDL-C (mg/dl) & 123.7 & 44.4 & 124.9 & 43.3 & 0.116 & 101 & 0.908 \\
\hline
\end{tabular}

Significant $\mathrm{p}<0.05$ 
TABLE 4: CARDIOVASCULAR RISK AND ASSOCIATION WITH GENDER

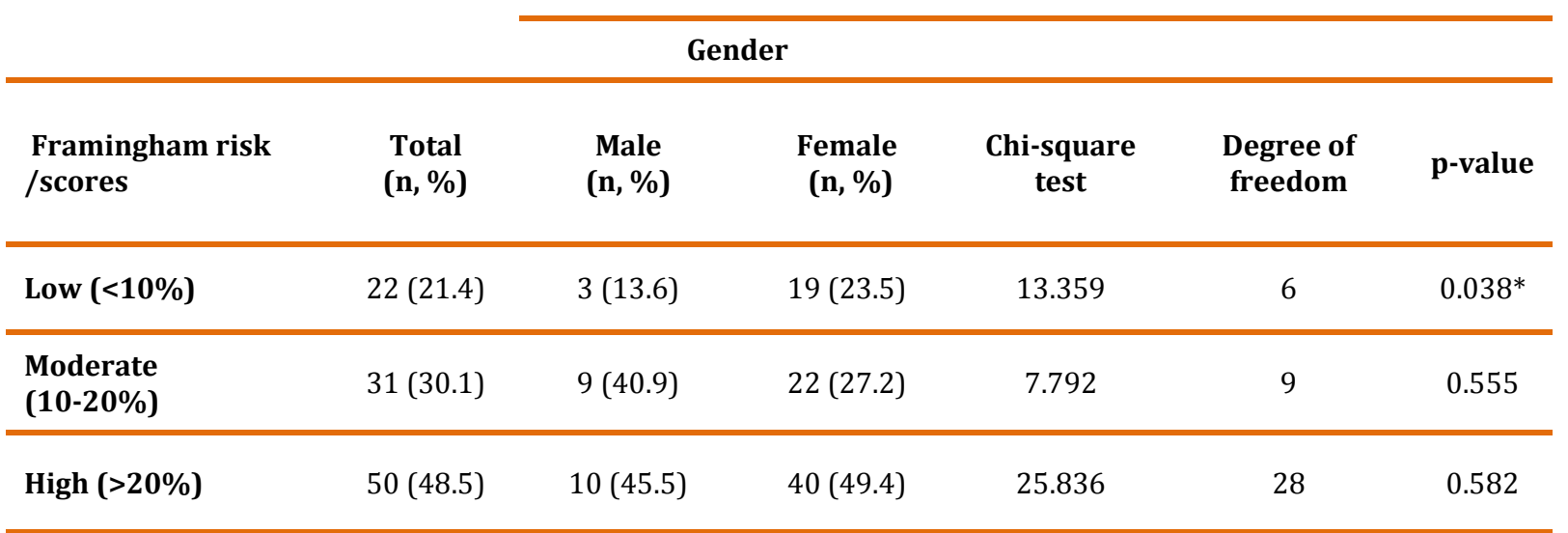

*Significant $\mathrm{p}<0.05$

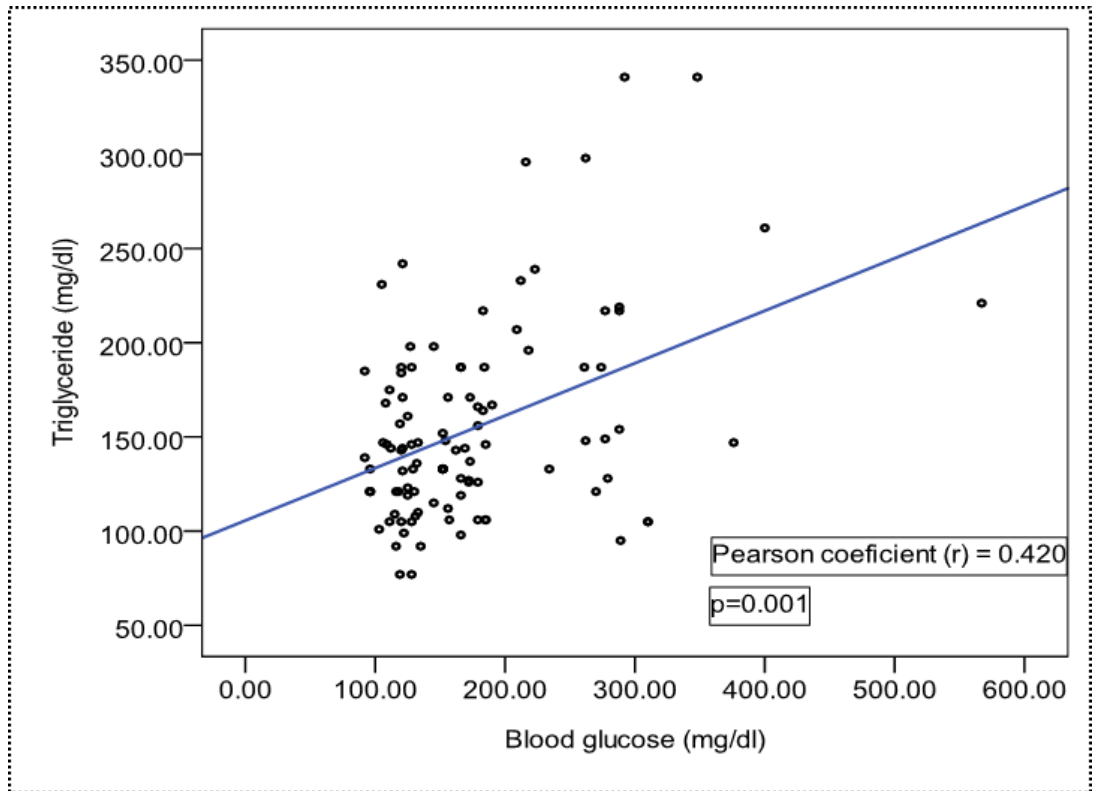

FIGURE 1: CORRELATION BETWEEN BLOOD GLUCOSE AND SERUM TRIGLYCERIDE LEVELS

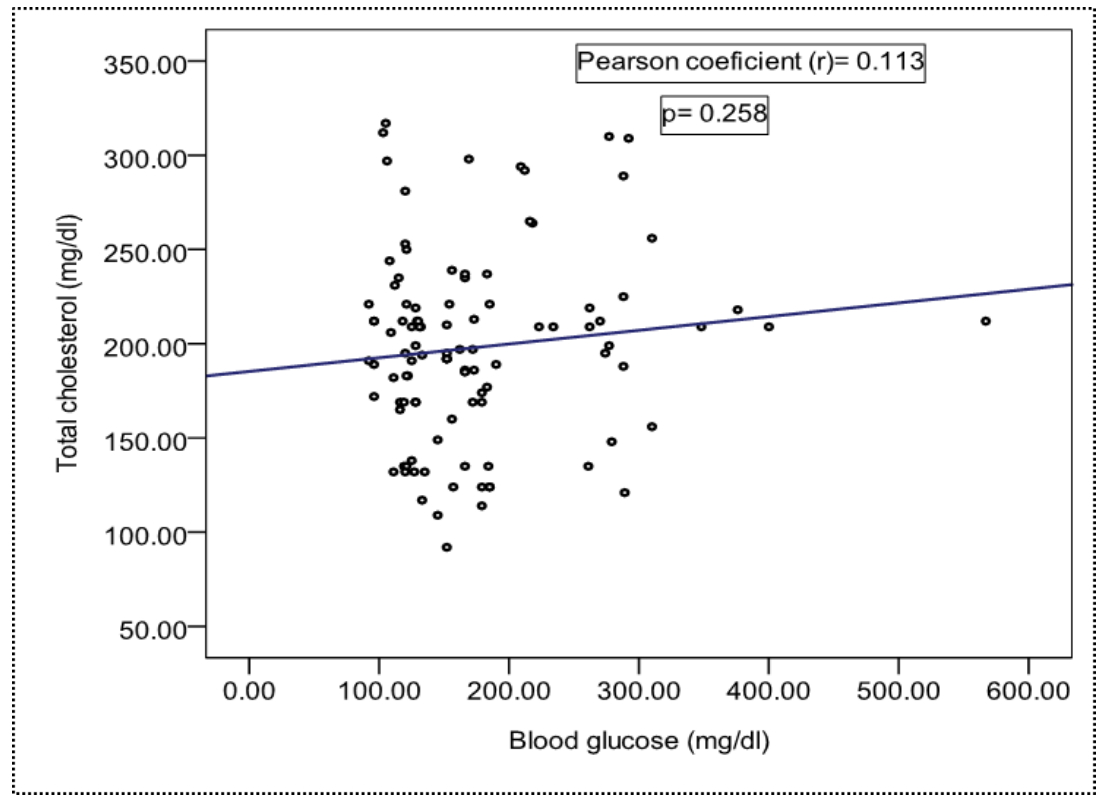

FIGURE 2: CORRELATION BETWEEN BLOOD SUGAR AND SERUM TOTAL CHOLESTEROL 


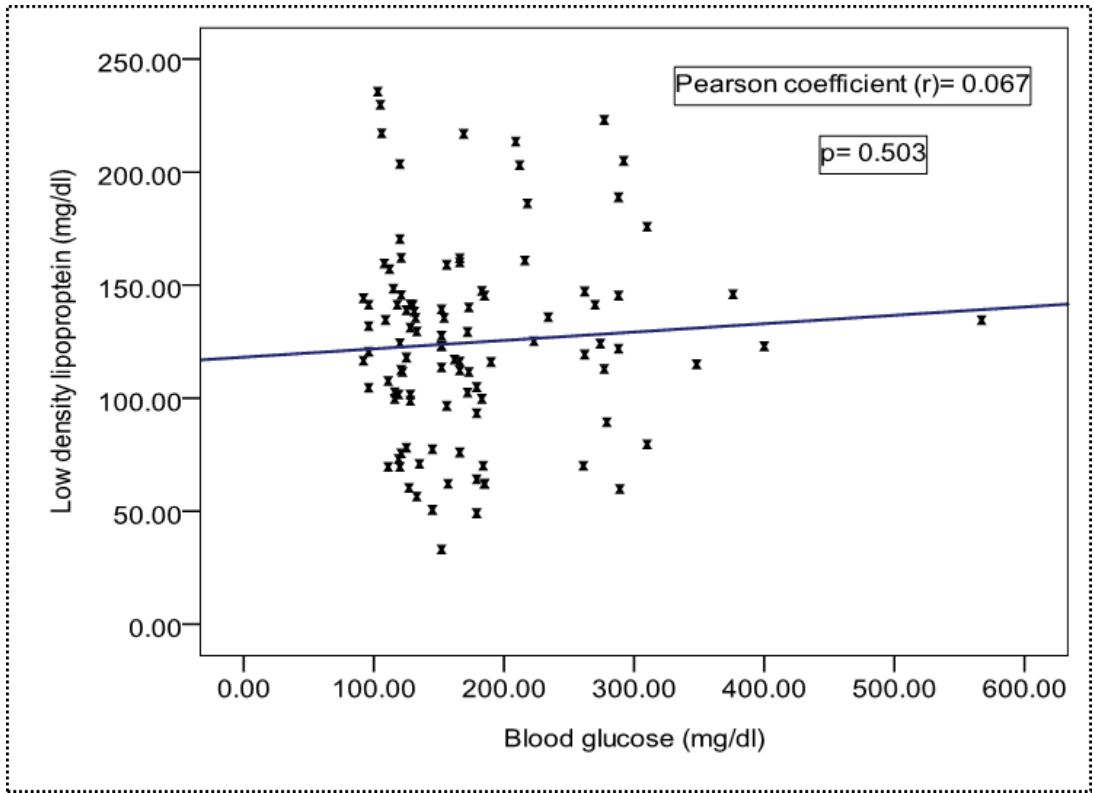

FIGURE 3: CORRELATION BETWEEN BLOOD SUGAR AND SERUM LDL-C LEVELS

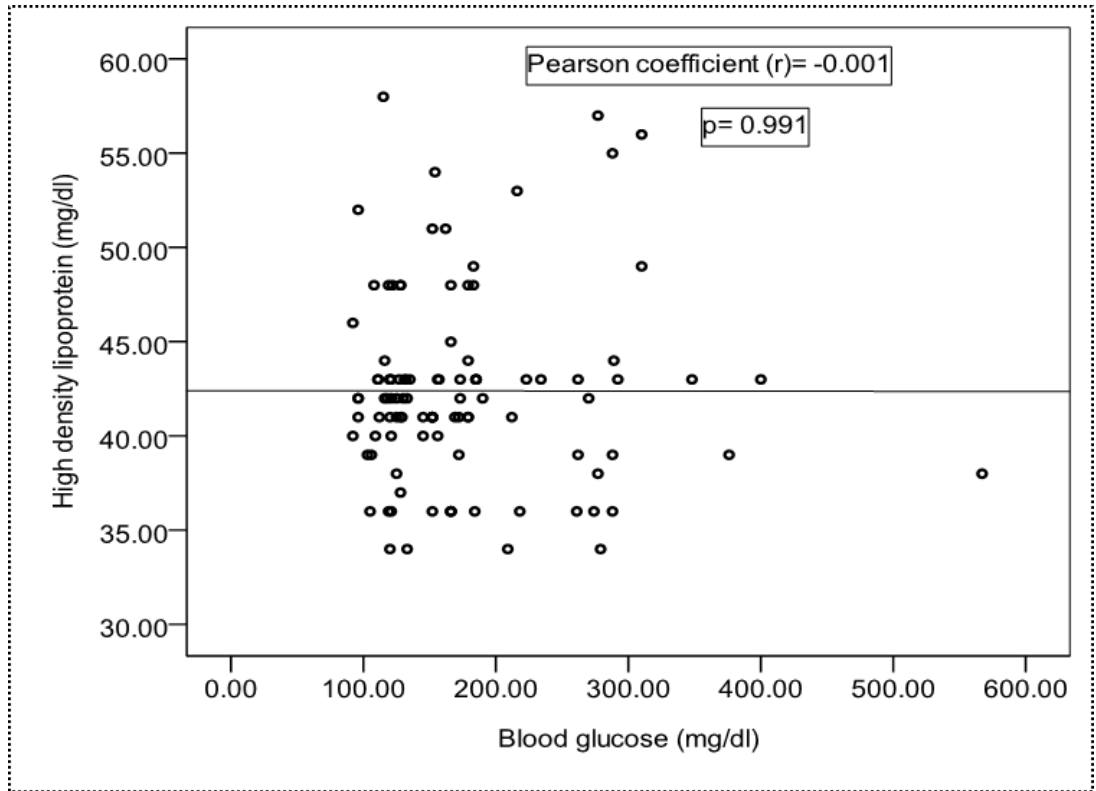

FIGURE 4: CORRELATION BETWEEN FASTING BLOOD SUGAR AND HDL-C LEVELS

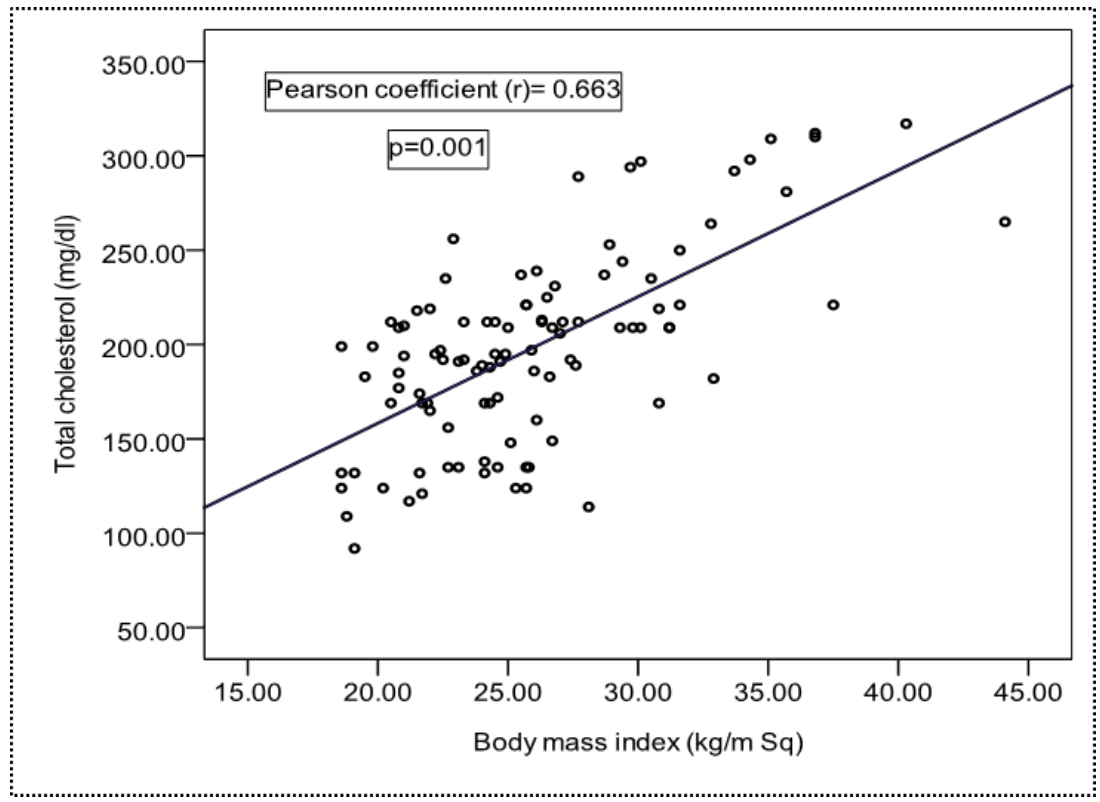

FIGURE 5: CORRELATION BETWEEN BMI AND SERUM TOTAL CHOLESTEROL 